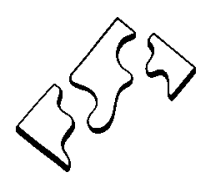

\title{
Phenomenology, Social Science and the Social Service Professions: The Case for the Integration of Phenomenology, Hermeneutics, and Critical Social Theory (A Reply to Luckmann \& Giorgi)
}

\author{
Dieter Misgeld \\ Ontario Institute for Studies in Education
}

\section{Reply to Luckmann and Giorgi: Phenomenology, Hermeneutics, Critical Social Theory, and the Social Service Professions ${ }^{1}$}

In his essay on "Common Sense, Science and the Specialization of Knowledge," Thomas Luckmann examines the relation between common sense and science. He proposes that a description of the respective structures of common sense knowledge and of scientific knowledge is useful because it will "provide some criteria for the assessment of common sense and science, clarifying at the same time their relation to one another" (1983, p. 59). Phenomenology is employed by Luckmann in order to show how common sense and science originate in human consciousness. Both types of knowledge are also to be considered from the point of view of the sociology of knowledge.

By combining the descriptive perspective of phenomenology with the analytical and historical orientation of the sociology of knowledge, Luckmann sets the stage for an important question about the place of science in social life. He asks whether there still isn't "much to learn about the limits set to the possibility and perhaps even desirability of infusing science, distinctly a form of specialized knowledge, into common sense" $(1983$, p. 70$)$. At the end of his essay he briefly answers this question. He doubts whether the applications of science which have entered into everyday life in most contemporary societies have made conduct more rational (p. 72). And he also regards it as unlikely that scientific cosmologies in their entirety can be transferred to common sense (p. 72). The knowledge required to regulate action in ordinary situations cannot be provided by science alone. Thus, all one can do is to "alternate from the naive attitude of everyday life to the theoretical attitude of science and back" (p. 73).

I regard the proposals made by Luckmann for a study of the relation between common sense and science as useful and informative. I am especially impressed with the proposal that an appropriate clarification of the relation between common sense and science cannot be achieved by exclusively adopting the orientation of phenomenological research.

By including the sociology of knowledge in an examination of the relation between common sense and science, we gain an historical vantage point, with reference to which we can identify the changing relation between common sense and science. We can raise questions about the place of common sense knowledge and scientific knowledge in contemporary society which phenomenological inquiry as such does not convey. For phenomenology in its purest form does not provide readings (Taylor, 1971) of our cultural situation, which help us relocate ourselves with respect to the relation between common sense and science as an area of major cultural conflict in contemporary society. This argument applies to those 
forms of phenomenology in particular which are still committed to the pursuit of a "science" of the social lifeworld in Husserl's sense.

Thus, Giorgi, in his reply to Luckmann, endorses Husserl's project. $\mathrm{He}$ says that by making the lifeworld the subject matter of a science of its own, in Husserl's sense, the "respective meanings of science and common sense" can be clarified "since they both emerge as themes for a more foundational science. They cannot really judge each other because they are both parts of a larger context" (1983, p. 85).

While there obviously is a need to clarify the subjective meanings of common sense and science, Giorgi fails to see, I think, to what extent it is a fact of contemporary culture that science and common sense have already judged each other or are being judged in their respective significance by the dominant processes of social transformation. And this isn't just a question of their subjective meanings. This criticism stands even if Giorgi recognizes that, for example, scientific psychology requires the suppression of common sense as a possible way of knowing about people and their conduct (e.g. 1983, p. 81).

Giorgi doesn't notice that any systematic and descriptive examination of common sense and science in all their forms (this was what Husserl intended with the project of a transcendental phenomenology, including regional ontologies such as the one of the lifeworld) comes too late with respect to our historical situation. Common sense reasoning in everyday life, at least in industrial societies, is already under the sway of scientific or quasi-scientific modes of reasoning, which undermine the very validity of common sense beliefs once foundational for practical orientation and cultural understanding. The cultural traditions, which support these common sense orientations, are undermined. They consist in a set of common conditions determining the meaning, for example, of childhood (e.g. Suransky, 1980) and of adulthood (as well as the relation of both). These cultural traditions also provide a framework for the articulation of needs which enable people to interpret their needs with respect to common beliefs about what is just, right, and good, independently of professional intervention and professionalized systems for the delivery of satisfactions (e.g. Illich, 1978). Cultural traditions and common convictions understood in this sense consist of sets of common meanings not reducible to what is subjectively understood. Yet, they would have no sense whatsoever were people in the society unable to orient to them through accounting for their meaning subjectively.

While Giorgi does not do justice to the presence of common meanings in social life and to their irreducibility to subjective meaning intentions, Luckmann, as a sociologist, is closer to the phenomenon of meanings held in common. He notes that practical orientation frequently is dependent upon global interpretations of world and human fate, with respect to which religion, for example, and scientific world views stand in a relation of (probably) irreconcilable conflict.

At times he seems to move the project of a phenomenological sociology established by Alfred Schutz toward a rapprochement with the positions of hermeneutics and that of recent critical social theory as a theory of 
communicative action and as a critique of the invasion of the social lifeworld by systems-theoretically conceived techniques for the management of the economy and of administrative power (Habermas, 1981). At least some of the questions raised by Luckmann, Gadamer, and Habermas are quite similar, no matter how much their methods of analysis and their answers may differ.

Phenomenological sociology (Luckmann), Hermeneutics (Gadamer), and Critical Social Theory (Habermas) all propose that an inquiry into the historically variable relationship between common sense and science is required if we are to reach conclusions about a practical orientation to the future of our society. All three differ from Husserl and from Giorgi's call for the renewal of the orthodox programme in phenomenology (i.e., of transcendental phenomenology).

But while Luckmann still leaves the descriptive orientation of phenomenology untouched thus, at least, not breaking with the expectation that a complete descriptive account of the social lifeworld can be achieved, Gadamer (who builds on the early Heidegger) and Habermas concentrate on interpretations of our contemporary cultural situation, which require the translation of descriptions of it into arguments which can inform practical deliberation.

Thus, they would wish Luckmann to strengthen his concluding deliberations: Rather than merely argue that one must alternate between common sense and science, and to simply note that the conduct of people in industrial societies may not have become more rational since the Industrial Revolution (because we know how to use cars, electricity, etc.), he would be asked to argue the case of a more encompassing form of rationality. With critical social theory and hermeneutics one would ask whether employing technologies or having technical knowledge can at all be expected to alter the practical conduct of everyday life in other than technical ways. Thus, hermeneutical and critical theorists can argue (as the orthodox insistence on interminable description in phenomenology cannot) that wherever scientifically directed or technical action and scientific or technical reasoning are regarded as the only viable form of practical action and of practical reasoning, we are faced with the influence of a technocratic ideology and with scientism as an ideology. We are also faced with a form of cultural invasion (Freire, 1971): the invasion of the social lifeworld by the imperatives of rationalized organizational forms, such as economy and bureaucracy, (Habermas, 1981, Vol. 2).

As soon as one is aware of the relevant phenomena, one can no longer remain exclusively committed to merely descriptive phenomenology as both Luckmann (building on Schutz) and Giorgi (following Husserl) are. Here I agree with Beekman (1983) and Suransky (1980) with respect to the need for reconsidering phenomenology. One would be compelled to translate theoretical insights into practical questions. One will no longer separate research from cultural action and social struggles even if one recognizes that these are not the same. We need to inquire into the point and the possible limits of descriptive accounts of various social situations. This inquiry will regard itself as contributing to a critical pedagogy in Freire's sense. ${ }^{2}$ Its practice has been anticipated in the reformulation of the 
notion of self-formation (Bildung) coming from German idealism by Gadamer in his Truth and Method (1974) and by Habermas in his Knowledge and Human Interests (1970). In spite of the fact that both philosophers differ with respect to the meaning and force of reflection as a process for the extraction of meaning from social situations and cultural traditions (Misgeld, 1976), they agree on one essential feature: The interpretation of history and culture has a practical point. The point is to indicate an interpretative understanding of our present cultural and social situation which helps us come to terms with it by appreciating it more deeply with reference to its history (Gadamer) and/or by learning to recognize those collective illusions at work in it which undermine the capacities of reflection to initiate critically transformative interventions (Habermas; e.g. Misgeld, 1978). ${ }^{3}$

A critical pedagogy erected on this basis aims at the development of cultural understanding and cultural action with respect to selectively determined situations. The situations to be singled out are those in which scientific expertise and general cultural knowledge already are in conflict. A critical pedagogy will direct itself toward the making conscious of these conflicts and avoid facile reconciliations. It places itself at the centre of the conflict in question without relying on an Archimedian point such as the epistemological framework of transcendental phenomenology (Misgeld, 1981a). Thus, it also endorses Heidegger's early critique of this framework. This critique identified the central question of hermeneutical understanding as a question of the orientation we take toward ourselves by taking an orientation toward things and persons. It regarded the question of existence to be determined in the practical attitudes we take toward ourselves and the finiteness of our existence: Theory is second to the understanding achieved in practical orientation.

Thus, a critical pedagogy will employ phenomenology for the sake of clarifying and sirengthening this practical orientation. It aims at the formation of critical and interpretive competence in the practice of reflection. Descriptions and theories will be entered into a conversational process of deliberation which tests the limits of commonly shared but also contested convictions (Misgeld, 1983). Rather than just move back and forth between common sense and science, as Luckmann suggests, in order to establish the validity of scientific and common sense beliefs, one vis-à-vis the other, deliberation intends the resolution of cultural conflicts by aiming at broader and more encompassing understandings: Normative convictions about what life can be like in society are its aim. Normative convictions about what is right and just, for example, about what is owing to people, reach beyond science and common sense. Both scientific or technical expertise and the ordinary taken-for-granted knowledge of everyday life are regarded as problematic with respect to those situations of conflict in which the point of either science or common sense is in question.

Conflicts occur with some regularity in "developed" industrial societies in those areas where professional knowledge encounters an everyday or lay understanding of cultural situations (Gadamer, 1976; Habermas, 1981). I am thinking in particular of social service professions such as social work, nursing, teaching (education), psychiatry, and applied psychology 
(therapies of various kinds). In all these cases the professional practice in question objectifies the phenomenon in question. It thus denies that cultural situations are at all validly understood before the methods of research informing professional practice are applied to it. But it is also the case that practitioners in these fields of professional knowledge frequently protest against the encroachment of scientific methods (and of administrative rationalization guided by it) upon their activities. In many cases, teachers, social workers, health care workers, and sometimes even medical practitioners may still regard their relation to their clients as a moral relationship. Its basic features are distorted or disappear from sight as soon as the practice is thoroughly professionalized.

These are the cases of cultural conflict which I have in mind and which phenomenological research must address. Rather than half-heartedly taking a middle road between common sense and science as Luckmann does, or once again pursuing the elusive programme of a phenomenological "science" (universal knowledge), one can turn to the exploration of particular situations and practices in order to see the force of historically generated convictions underlying them. We can hope to instill a respect for the "phenomena," i.e., the intents, activities, and life-histories of those to whom a professional practice is addressed and by whose conceptions of their situation it must be guided.

In this sense, I am tempted to say, a "hermeneutically enlightened" phenomenology which is aware of its own limits can contribute to a view of the professions, a view which is more supportive and less utopian than the one favored by their most severe and frequently incoherent critics, such as Illich. However, phenomenology can also provide insights into the professions and their relation to everyday knowledge-insights which compel us to examine the cases, situations, and activities with respect to which professional knowledge is to make a difference. Phenomenological inquiry can help us understand that it cannot be professional knowledge as such which determines the reasons and aims of professional intervention. It can convey the sense and meaning of activities as they are known in life-when life is not yet regulated by standard requirements of a professional practice. It can allude to and evoke the understanding we have of life when we are not yet entirely under the sway of those conceptual and technical exigencies which force us to subsume events and actions under general rules, procedures, and policies. Thus, an additional consideration emerges from our discussion. Insofar as it is scientific, knowledge in the professions must be based on one or the other concept of general laws of human behaviour. It rests on a belief in the possibility of discovering general laws. Scientific knowledge employed in the professions also requires the confidence that law-like knowledge of the regularities of human conduct provides the means for vigorously predicting the effectiveness of professional intervention. Thus, a highly problematic view of the predictability of human behaviour underlies this position (MacIntyre, 1981).

But more importantly, professional practice is not merely the application of scientific knowledge acquired from it independently. For the practice of the professions is subject to administrative and political 
controls which regulate the use of scientific knowledge in the professions and favour some forms of knowledge over others. Most modern corporations and public administrations, in fact, do not employ scientific knowledge in order to critically examine their political and bureaucratic practices. They employ research in order to strengthen these practices. One merely has to think of the large amount of research carried out by military intelligence and corporate research and development establishments. Such "scientific" research only serves the interest of increasing the power of these establishments.

The social service professions are not, of course, subject to the same policies or controlled by the same interests as are corporations or the military. But, in their case as well, scientific research mostly does not translate into a critique of the power gained through the professionalization of the activities meant to help people to mature (education), to stay well or become well (health), or to cope with a variety of injuries and disadvantages which afflict those who have a weak position in society (social work). The "helping" professions (Illich) frequently do not help their clients. They contribute to the rationalization of administrative practices applied to groups seen as in need of professional treatment by the administrative agencies of modern societies. This is not to say that the practice of a social service profession never does any good. I am arguing, however, that we need an analysis and interpretation of the professional practices of education, health care, and social work in order to see how the intention to help is regulated by the fact that practitioners in these professions on the whole cannot, autonomously and in open interaction with those whom they intend to assist, develop the knowledge needed for their practice. The administrative and political controls surrounding their practice require that they regard it as an application of scientific knowledge. So, the orientation of professional practice contributes to its transformation into forms of administrative management. Thus, a critical reflection on professional practice requires the employment of phenomenology, hermeneutics, and critical theory (as a theory of communicative action and of social discourse) in order to illuminate the problematic character of a "scientization" of social practice. For only these orientations provide strong alternatives to a presumably predictive social science.

It remains for us to look into some examples of the peculiar blending of "social science," administrative/bureaucratic rule and professional practice. We need this discussion in order to direct critically oriented phenomenological and hermeneutic inquiries toward the convergence of these three aspects of a scientifically rationalized practice of the social service professions.

We need to interpret the convergence of these elements as representative of the alienation taking place in the social service professions from any reasonable conception of human and social service. It will become apparent that the social service professions must cut themselves loose from the dominant managerial orientation in the professions. They need to become more independent from the administrative machinery available in societies which are fully or partially committed to "welfare state" policies. 
In section II of this paper I will consider two examples in order to illustrate the issue. These are: (a) proposals for the technical/instrumental rationalization of education by transforming education into a fully pre-plannable process of instruction, and (b) sociological systems theory as a theory of organizing the penetration of all spheres of life by technical/administrative or managerial reasoning. By considering both examples we can identify the force of the relevant conceptions on a highest, most abstract level (sociological systems theory) and on a most mundane, technical/practical level (rationalization of instruction). Inquiring into both will aid phenomenological research of the kind described in identifying the cultural limits to a rationalized and rationalizing managerial practice of the professions which destroys the very reasons for its existence: the need for help, advice, and learning. For we can assume that everyone has need for them at some time; we may not assume that a professional treatment is readily plausible and benefits those who have these needs (Illich, 1978). In considering the two examples mentioned, I shall also turn to Habermas' most recent work (1981) as indicative of a turn in critical social theory toward phenomenology and hermeneutics. I shall also propose modifications in Habermas' position which bring it even closer to a hermeneutically reformulated phenomenological orientation.

\section{The Technological and Administrative Invasion of the Social Lifeworld: Instructional Technology and Sociological Systems Theory}

In the actual world of social relations and in our relation to the natural environment, technologies abound. There is hardly an action of any consequence which does not rely on a technology of some kind. The technologies in question are not just technologies dealing with material things and their properties in the widest sense, but also what we may call social technologies; technologies for organizing relationships between people in a manner similar to the mode of organizing characteristic of technologies establishing relations between things and their properties.

Usually these social technologies have the form of administrative procedure, or, as in the case of new educational technologies, they have similarities with both bureaucratic administrative procedures and "scientific technologies." This applies, for example, to instructional technologies which categorize instructional objectives and provide for the evaluation of learning performances with reference to standard conceptions of instructional outcomes. The organization of these technologies provides the frame for the production and use of computer technologies applied to education or to the workplace.

Instructional technologies are organized around the ground-rule of sufficiently externalizing human action and interaction so that action and interaction become analyzable with reference to standard conceptions of motive, interest, and skill, as well as to standardized conceptions of achievement (categorized in terms of testing requirements). Thus, educational transactions, encounters between persons, and heterogeneous work environments can all be made to interlock. They can successively be integrated into an order of human activities, the properties of which are defined increasingly with reference to the most stable organization and most permanent surveillance (Foucault) of these activities. 
Systems-theoreticians claim that only this organization of human activities permits the continuous and successful management of social relations through and across the various boundaries of sub-systems as organized, yet separable, spheres of activity.

Instructional technologists and advocates of competence-based learning want to increase efficiency in education by introducing behavioural technologies into schools and colleges, thus providing for greater accountability, i.e., greater public inspectability of efforts in teaching and learning.

Management consultants have similar aims for the organization of workplaces in industry and government. All these advocates of new management technologies link efficiency with the accountability or inspectability of action: in short, its controllability.

On the whole, so far at least, these developments give rise to increased controllability and manageability of actions and activities from outside the horizons of meaning, or the context of activity, in which actions and activities make sense to those undertaking them. They acquire a meaning, i.e., an operational definition of their sense outside the meaning and significance that activities have and acquire in the situations in which agents can see themselves as generating in order to realize meanings.

The reorganization of education, work, and possibly leisure in terms of the social technologies mentioned may be intended and have as a consequence a centralized form of the controllability of action and interaction in society. It may increase supervisory capacities in the form of their managerial control. This would amount to a more anonymous and rule-bound form of control or rule than any classical form of political domination based on a monopoly of force (violence) has been. Or it may take the form of the increasing decentralized dispersal of control such that many of us, especially the middle and professional middle classes, "participate," i.e., have a significant share in the refinement of systems of accountability via the regimentation of tasks and processes once holistically conceived.

A mode of social organization might emerge, in (over-) developed industrial societies and post-liberal, mass-democratic states, which increasingly transforms the tasks of organizing social relations, through the use of language and with reference to custom-bound ways of doing things, into management tasks with the attending requirements of information assimilation and control. I am thinking of a system of feedback control. It amounts to the refinement of techniques for the rationalization of action and interaction. More and more social action is assimilated into the model of strategic action (Habermas).

The social scientific utopia of sociological systems theory regards increasing feedback control as the very hallmark of increasing rationality. Nothing could be more rational than the organization of society in terms of (a) the increasing interdependence of all individual human actions and of all subspheres of human action, and (b) the increasing ability to monitor this interdependence with reference to the systemic properties of action-occurrences. 
Niklas Luhmann, a prominent contemporary theorist of society as a system, ${ }^{4}$ can say:

The function of system differentiation can be described as the enhancement of selectivity, that is, the increase in available possibilities for variation or choice. Societies (at least modern society) can presuppose an infinite world. On this basis, they create a highly contingent and dynamic but nevertheless already domesticated internal environment which serves as a condition for the development of further social systems. (1981, p. 231)

The management problem which this conception of societal development indicates may translate into the management of expectations which individuals or organizations have with respect to other individuals or organizations. For "expectations have to be changed frequently at appropriate levels" (Luhmann, 1981, p. 250). Goals, values, and rules must be distinguished. Persons, while remaining individualized, must elaborate the relation of values, goals, and roles into plans or programs as do organizations. On the foundation of a twofold contingency, the uncertainties in the relation between alter (others) and ego (myself) increase. They are due to the functional desirability of not linking expectations mechanically or through one centre of control. Yet interaction is also more secure, insofar as alter can know the plan or program I follow (e.g., as a member of an organization). $\mathrm{He} / \mathrm{she}$ can know what my expectations are.

Criteria of organizational and systemic (sub-systems) membership come into play. Essential here is the management of time for the production of plans and programs: "Functional differentiation leads to a condition in which the genesis of problems and the solution to problems falls asunder. Problems can no longer be solved by the system which produces them" (Luhmann, 1981, p. 249).

There is, on the level of sub-systems, less autarchy and self-sufficiency but higher autonomy in applying specific rules and procedures to special problems. This means that interdependencies have to be mediated by time. Functionally differentiated societies need more time but have less time available than older societies. Their history, as well as their future, is much more complex and contingent than that of any previous society. (Luhmann, 1981, p. 249)

And history, as such, has no goal (cf. Luhmann, 1981, p. 323).

This streamlined account of the functionally differentiated society does not endorse the management-conception of hierarchal and centralized control. It limits itself to praising the virtues of differentiation; thus management becomes everyone's problem. To learn to distinguish between personal interests and the functional requirements of an organization is only a beginning. To manage time in all realms of activity; from personal life to, let us say, investment decisions, might be the ultimate form of functional specification, the translation of a systems-requirement (a requirement of social evolution) into a practical task for individuals and organizations. Thus, the overall goal to be pursued in a person's actions or group of people's actions is the advancement of the organization of all social activities into systems-relationships.

The ultimate warrant for the application of management conceptions to social practice is an increase in overall rationality as the increasing 
differentiation, yet also interdependence, of sub-systems of society, or of action in the society. This is not a goal to which one can have a relationship of responsibility other than through an office, a role, the externalized system of accountability. Less ambitious forms of management theory (instructional technologies, etc.) endorse it as well, as we have noted.

The systems theory of society and a behavioural programme for the formulation and evaluation of educational objectives, let us say, both can agree that there is one problem in the communicative relations of societal members which requires certain steering mechanisms to intervene: It is the problem of organizing social relations such that boundaries can be drawn for behaviour to become acceptable (cf. Luhmann, 1981, p. 345). Instead of treating the managerial orientation of action as a matter to be addressed by societal members through their spontaneous organization of their relations, the reorganization of their relations with reference to the concept of system suggests a conception of the management of social relations. The meaning of behaviour in instructional sequences, for example, can be analyzed as a property of the societal sub-system of education such that the very differentiation of this sub-system as an organization of activities has boundaries specific to it.

The open horizon of what can count as educationally generated meaning and the meaning of education is transformed into the production of instructional sequences as the very way in which education as a socially delimited activity acquires determinate properties. Making the meaning of education controllable this way is itself the achievement of a theory which selects from among the range of theoretically conceivable possibilities having the particular problem of the selectivity of behaviour in view. Instead of raising the question of what education could mean, i.e., why and how it can be valued, education becomes the instruction needed for "selective processes of experience and action to be organized in such a way that their selectivity can be understood, managed, readjusted" (Luhmann, 1981). This programme is quite compatible with democracy. The issue is not that there be a centralized system of supervision of educational activities, but that the open horizon of the meaning of education be adjusted to the meaning education can have insofar as meaning becomes a property of the systemic organization of educational activities. It becomes a management problem as well as a manageable problem. This can be achieved by translating reflections on education which teachers might entertain, reflections on what the intrinsic meaning of education is or what is entailed by the concept of education, or what the societal significance of education is, into a more restricted set of analytic tasks. "A first step in preparing instructional objectives is to determine what kinds of learning outcomes are devised for a given unit of instruction" (Kibler et al., 1980, p. 81).

The point of this formulation is not so much that it recommends a procedure for checking whether one has carefully prepared one's materials, formed realistic expectations with respect to what can be learned, etc., but that "the formulation" of instructional objectives stands in lieu of a more comprehensive reflection on education. It is also to replace any occasional reflections on learning and teaching as they arise from a 
particular educational transaction with a standardized form for carrying out the monitoring of instruction. Thus, the formulation of instructional objectives doesn't merely instruct the teacher in how to plan a lesson, etc. It is geared toward evaluation as a necessary component of the formulations of instructional objectives in the first place.

A skill is no longer a competence, indicative of a capacity or a potency, an ability to do something, but the bit of behaviour identifiable in a certain range which, by the application of diagnostive/evaluative tools, measures or scores the mastery of an instructional unit.

I am not, at this point, concerned with the possible undemocratic character of the reorganization of teaching and learning indicated by this procedure. Nor am I concerned with the apparently anti-intellectual consequences of such a programme for planning educational accountability. For, in principle at least, teachers can become somewhat autonomous planners and managers of such instructional sequences-even if that is unlikely, practically speaking, nor strongly suggested by some of the literature.

I had already stated that Luhmann's theory of the management of systems-boundaries is neither antidemocratic nor undemocratic insofar as it does not argue for a centralized system of surveillance but for a constant process of reciprocal monitoring, distributed across the relations of interdependence between the various sub-systems of the society. I am arguing and will now address this matter as a highly contentious issue that teaching and learning, education, in short, are translated into management tasks. This means that an administrative conception of what it means to account for social action, in this case for educational transactions, becomes the only one with reference to which educational activities can be accounted: that is, elucidated, explained, justified, explicated, etc. This means the primacy of a mode of reasoning oriented to the exigencies of an administrative organization of educational efforts. It also means the potential irrelevancy of modes of reasoning concerned with the difference between the intrinsic or the extrinsic value of education, the logic internal to the concept of education, ideals of educational value insofar as they are seen to supervene organizational exigencies, etc. The administrative reasoning which I characterized (as it occurs in the formulation of educational objectives) transforms teachers and learners into appendages of a process controllable from outside the educational transaction in which both are involved and are engaged with each other as subjects initiating questions and answers, making proposals for the solution of a problem, and criticizing these solutions. The very flow of criticism and unimpeded communication which we still associate with the idea of education (insofar as we connect it with the idea of a community of inquirers) is subjected to regulation oriented to the rigid accountability of what occurs in educational transactions. Each step in their development is open to inspection by someone outside the process, especially those who have the special task of monitoring it. These are the managerial authorities in control of public funds and/or in control of the design and application of the pertinent research technologies. 
But I do not mean to argue for a form of collective action, on the part of teachers' associations, for example, intended to contain the possible downgrading of teaching as a profession, which might be the consequence of these proposals. Politically, in fact, one can argue that many teachers already see themselves so much as administratively mandated dispensers and distributors of learning materials that not much of substance can be lost beyond what has been lost already, and at least a modicum of enforceable accountability can be gained.

The danger really lies in something different. It is the erosion of those very communicative resources which are constitutive of the formation of societal identities, of social settings maintained in an open flow of interactions, and, of course, of the potential for a critical reasoning which overflows the systematically controllable and directable boundaries of organizationally linked activities, as well as of the potential for imagination so badly needed for any thinking about a future different from the present. This is the field of resources to which phenomenological and hermeneutical thought has applied the term lifeworld (the world of everyday life, or the social lifeworld).

With Habermas (1981), we may understand the developments characterized so far as a colonization of the world of everyday life, as a penetration of its native forms of reasoning by a reasoning exclusively responsive to the exigencies of technological and administrative steering and control mechanisms organized into a ruling apparatus (Smith, 1980).

And for a theorist like Foucault, an anonymous system of surveillance emanates from the discourse of the social sciences, bringing about the application of technologies to social conduct which legalize and medicalize its very meaning.

Many contemporary formulations (academic or not), in fact, suggest the penal colony, the insane asylum, or other closed institutions as metaphorical analogies to the present situation of society and even more to its future. These analogies apply insofar as we can imagine what it would be like for a society to be completely regulated by techniques based on the systematic misunderstanding of human action which is so characteristic of the social sciences (cf. MacIntyre, 1981).

For Habermas, the tradition context of language (Misgeld, 1976) and the cultural (normative) background of everyday reasoning provide the foundation for analysis of the new forms of cultural invasion mentioned. For he claims that there is a confrontation between the autonomous communication structures of the social lifeworld and the media for the coordination/integration of social action. The latter do not seem to rely on these very structures of communication. For Habermas (following Luhmann in this respect), money is such a strong medium. And so are bureaucratic procedures. Bureaucratic methods, for example, or the increasing procedural mediation of naturally ordered (naturally occurring) activities (as ethnomethodologists would say), such as communicative sequences in educational or pedagogic settings, stand for an abstract and strategic re-ordering of communicatively generated relationships. 
Let us look at the formulation and evaluation of instructional objectives once again by selecting an example of an instructional unit: Let us say, you were to ask a social science teacher what his/her objectives were for his/her government class and he/she responded as follows: "I want to make my students better citizens." You could agree that this was a reasonable and legitimate obective. But, as a matter of fact, in the course of instruction this apparently profound aim really amounts to no more than the attempt to promote "the learner's achievement on a true-false test" (Kibler et al., 1981, p. 11).

The logic of the specification of instructional objectives requires the translation of global expectations with respect to learning outcomes into operational statements which provide for the possibility of a piece-by-piece, detailed evaluation of the achievement, the actual attainment of the outcome. In itself this procedure may even be helpful for distinguishing between actual attainment and only conjectured attainment of a learning goal. It may also serve to distinguish trivial from more profound and encompassing learning goals; thus, helping teachers avoid the unnoticed substitution of more demanding objectives, such as "good citizenship," by rather trivial ones, such as correct answers on a multiple choice test.

But our problem lies deeper. The assault on the communicative structures of the lifeworld entailed by this reformulation of educational goals and practices lies in their reformulation of more open-ended communicative and deliberative practices into definitely planned for, segmented, strategically organized bits of intervention. It is not as if language as the medium of communication is suppressed or eradicated. Even a fully computerized process of individualized learning no longer requiring the constant presence of a teacher would not do that. In this sense, Habermas' formulation is misleading for he sometimes seems to argue as if there were a threat to the communicative foundations of social organization as such. Thus he can say that there is a threat to the "symbolic structures" of the lifeworld (1981, Vol. 2).

When one translates this formulation into phenomenology, one would have to argue that the processes for the typification of practical orientation, which Luckmann (and Schutz) attribute to common sense knowledge, can disappear or that they can be replicated and schematically controlled by machines. One would also have to believe that Schutz's principle of the reciprocity of perspectives (that I know that I can see what you can see when I take over your spatio-temporal location) as constitutive of taken-for-granted knowledge in everyday life can be rendered superfluous. Were this possible, then the social lifeworld would indeed become senseless. We wouldn't know how to make sense of any event or action. But there is no reason to believe that technological rationalization can achieve the complete objectification of human action. At least its achievement would be indistinguishable from the destruction of human beings and their identities as we still know them. One may argue, however, on the basis of a phenomenological correction of Habermas' position, that it is indeed possible for the taken-for-granted features of everyday reasoning to recede further into the background of practical orientation. 
Technological alienation can alter our everyday understanding of them and deeply rooted common sense beliefs may become inconsequential for us. But this is a somewhat speculative consideration inspired by Habermas' somewhat unrealistic formulation of the issue.

With respect to the present situation, it is much more important to determine to what extent we can still rely on open-ended, fluidly organized practices of communication and deliberation, and to what extent we cannot. At issue, also, is the play we give to those beliefs about self and other which rest on practices not themselves up for detailed scrutiny, such as Schutz's reciprocity of standpoints.

As to the first point, in the course of educating a student to be a better student, a teacher in a teaching situation not yet streamlined according to the planning methods of programmed learning and instructional technologies might wish to raise questions with and for the student about the general meaning of citizenship. $\mathrm{He} /$ she would consider a variety of examples, from the case of a citizen complying with the rules of a constitutional state to a citizen critical of those rules and committed, in some cases, to the practice of civil disobedience. $\mathrm{He} / \mathrm{she}$ might point to the different forms of commitment involved, from a passionate commitment to some ideals regarded as of overriding importance to a generally indifferent and passive, but consistent, respect for law and order. $\mathrm{He} / \mathrm{she}$ might ask students to consider the strengths and/or weaknesses of each attitude. In the course of doing so, naturally, assumptions would come into play as Schmutz and Luckmann discuss them. They would come into play as indispensible beliefs about the reciprocity of obligations and rights as well as about the importance of regarding particular political functions as embedded in overall societal and moral concerns. These concerns refer to conventions for the maintenance of social interaction on the basis of the reciprocity mentioned.

The more open-ended the educational discourse about citizenship, the more questions can be raised. Then it is possible to ground an understanding of genuinely political questions in a more comprehensive, yet never fully explicit account of the network of social relations upon which the distribution of political participation rights rests, or of offices and procedures such as the legal arbitration of certain claims.

Much of this could, of course, be formulated with the specificity required by instructional technologies. The point about instructional technology is that, on the whole, its implementation could not be tolerant enough of the unexplicated yet always present suggestive possibilities which surround any particular articulation of a broader question raised. It will not be possible to see, after a while, what else could enter into an account of good citizenship other than the detailed instructional objectives planned for.

Critics of competence based learning, the so-called instructional objectives movement, and possibly also of computerized learning have, of course, noticed to what extent these methods may condemn students to be docile recipients of the planned instructional objectives. Philosophers, in particular, deplore the absence of a pedagogy increasing the cognitive, 
critical capacities of students. Philosophers of education (such as R. S. Peters and J. Passmore) rightly regard it as essential for the acquisition of critical capacities that students learn to appreciate the entire structure of knowledge, that they grasp the logic of the curriculum beyond being trained in particular segments of various curricular fields. And critics who have the political implications of the classroom in mind will observe how the social linkages and ligatures of learning are screened out when learning tasks are arranged and packaged in tightly structured units. Others concerned with the place of imagination in learning will find that the methods we are considering leave little room for the play of the imagination and thus may threaten the possibility of creatively transforming learning tasks.

It is more important at this juncture to consider in what way instructional objectives planning and programmed learning leave little room for the recognition of the embeddedness of learning and teaching in the communicative practices of daily life and transform both activities into goal-oriented behaviour. In order to analyze this further, I once more turn to Habermas.

Social action oriented to reaching understanding, he states, primarily takes place in language. We speak of an action as oriented to reaching understanding if we conceive of the actors as producing those actions (in speech) which require other actors to take a position with respect to the action proposed. They consent, disagree, dispute, confirm, etc. They behave as interaction participants. But, communicative action isn't merely a process of reaching understanding with one another. For actors also participate in interactions when they reach agreement about something in the world. They thus reveal their knowledge of states of affairs in the world while also confirming their membership in social groups and their own identity. Communicative actions aren't merely "processes of interpretation" in which cultural knowledge is laid open to a "test by the world." They also signify processes of social integration and of socialization (Habermas, 1981, Vol. 2, p. 211).

For Habermas, phenomenological analyses are restricted to understanding communicative action as a process of interpretation. They thus emphasize conditions of cultural reproduction which consist in the continuity of cultural traditions and the coherence of knowledge in everyday life. Crises of the phenomenologically understood lifeworld are crises of legitimation and orientation. They manifest themselves in the loss of collectively interpretable meaning.

The theory of communicative action adds two other dimensions to the lifeworld. Insofar as the coordination of action is at issue, the normative integration of social interaction is required. This is one feature of the social integration of the social lifeworld. The other central feature is the consolidation of the identity of groups: "The coordination of actions and the stabilization of group identities are appraised with reference to the solidarity of societal members" (1981. Vol. 2, p. 213). Disturbances and crises take the form of anomie, the loss of solidarity. In addition to social integration, the socialization of societal members internal to a social lifeworld must be considered. Socialization refers to generational or 
historical continuity, the integration of individual biographies with collective forms of life (p. 213). Its standard is the responsibility and accountability of persons. The failure of socialization shows itself in the drying up of resources for the formation of "ego-strength."

It is clear that this categorization of the dimensions of the world of social life places the concept of the lifeworld into the context of a communication-theory of social action which analyzes "the functions which an action oriented toward reaching understanding has for the reproduction of the lifeworld" (p. 216). We can then distinguish between structural components of a lifeworld, such as culture, society, and person, and processes of its reproduction, such as cultural reproduction, social integration, and socialization (p. 217). This makes it possible to claim validity for the concept of a lifeworld in all cultures and epochs. Then one can analyze the evolutionary history of societies and the history of the emergence and consequences of rationalization as a history of the relation and tension between systemic conditions of societal reproduction and its communicative interpretive conditions.

The systems-analysis of social reproduction is based on the perspective of an observer coming to the society from the outside (p. 227). It analyzes conditions for the "systems-integration" of society (action systems). Society becomes a "self-steering" system, relying on the generalizability of functions through media for the coordination of social action, such as money or bureaucratic/administrative power. These media do not call upon the communicative and deliberative resources of societal members in the full sense. Members are not expected to realize in their particular contexts of action the understandings needed for them to coordinate their action on the basis of their own independent insight. The systems perspective, therefore, is blind to the foundations of social integration in a lifeworld of communicative action, of meaning generated in interpretations and agreement achieved through deliberation and discourse.

But the perspective of communicative action focuses on the conditions for the maintenance of cultural reproduction, social integration, and socialization as they are known to societal members as interaction participants. It ties social theory to those perspectives which can be articulated by members of social groups themselves. Members are located inside the processes of the reproduction of society. They reproduce a world of communication and cultural meaning, a social lifeworld (p. 226).

This very systematic construction of the dimensions of society as a social lifeworld shot through by actions oriented to reaching understanding and threatened by the levelling and obscuring of these actions through generalized and generalizing media of social control is, I believe, highly suggestive for my purposes. I say this even if I have serious doubts that a systematic construction of this kind gives us a strong enough basis to bring into view what actually happens when those conflicts unfold for which Habermas identifies the most encompassing, generally relevant parameters. But the construction is suggestive for one thing because it makes us see that the introduction of programmed learning techniques and the like are intrusions into the communicative practices of daily life. It makes us see that there is a conflict between one mode of securing coordination of actions and another. 
Programmed learning and preplanned instruction so far primarily attempt to secure an interlocking of educational transactions, such that from the level of research and public policy-making bodies (ministries of education) through teacher education and the managerial supervision and evaluation of teaching and learning down to the level of teachers and students, all instructional activities can be linked with a set of uniform assessment procedures, providing for constant, thorough, and standardized accountability and controllability. Accountability of this kind finally integrates the activities of teaching and learning with an administrative system of policy enforcement quite similar to the organization of the dispensation of services in the welfare bureaucracy and in corporations.

The type of integration of all activities intended by models of programmed learning can only be meant as the organization of activities into a system controlled with reference to notions of administrative accountability. Teachers in particular are placed into the position of being anonymous dispensers of public goods with little opportunity to invest something of themselves into their work. In fact, one can conceive training programs on this basis which are no longer geared at all to education as such. They no longer begin from the basis that there is an interesting subject matter, attracting some people more than others, and which they want to teach because they feel people should know about it. Nor does one need a genuine interest in youth and young people as people whose growth matters, in some way, to those who teach them.

The book I have used for the discussion of programmed learning, etc. lays out reasons for the behavioural and operational formulation of instructional objectives and for their evaluation without ever considering, or even mentioning, different subject matters and what makes them worth learning. It also never considers concepts of the educated person or of the formation, through development, of the identities of learners as societal members.

Cultural reproduction, social integration, and socialization, however, have been and remain the most important dimensions of any theory of education which wants to show why we value education. The planning of instructional objectives is primarily concerned with increasing the efficiency as well as the controllability (by a modern research-dependent administration) of instruction, without at all considering that efficiency merely is one value among several essential for the reproduction of societies insofar as they are communities: that is, insofar as human societies need to secure some continuity of cultural traditions, some consistency of everyday actions and discourse, some kind of understood and appreciated solidarity between people, and some kind of critical, no matter how occasionally visible, independence of individuals and social groups from prevailing norms and conventions.

Habermas' analysis of the society as a social lifeworld constituted in communicative action provides us with dimensions for the study of the settings of educational activities which we can notice when we approach these settings from within, when we take the view of the participant in an educational activity. We can pose questions such as the following: What is the meaning of an educational activity, such as the teaching of reading? 
Why learn to read? What place does reading have in the history of the culture? What does it mean for people to be literate? Is this just a question of their having mastered what is a requirement of social positions, reflecting the overall requirements of an occupational structure, which, in turn, reflects necessary task orientations for the society? Or is there a personal side to literacy as well, just as much as an interpersonal, intersubjective one? This would lead into matters of socialization, i.e., the role of an investment of oneself, bringing oneself to expression in participating in the reproduction of the culture, as well as learning to understand the culture as leaving room for, even wanting, each of us to be himself as a member of the culture. Thus, the culture of one's community and society could become one's own rather than a sequence of learning tasks, the overall sense of which escapes us or is withheld from us.

And finally, questions of solidarity remain possible. If teachers can reflect with their students on the place of their educational activities in the composite of social relations to which they belong, they can reflect on and can practice solidarity with one another and other members of the society. They can develop commitments to values which they want others to share. No fully externalized process of instruction will leave sufficient space for teachers and students to fully assert and affirm their identities as members of a culture who don't just want to belong to culture and society as if they were forced to be members and as if what made them share in something was beyond their horizon of comprehension.

One can see, then, in what ways Habermas' system of distinctions can be helpful for a systematic, yet also practical, reflection on education. A fuller picture would include many themes addressed in educational theory, from the philosophy of education to cognitive developmental theories and studies of the social organization of teaching and learning. One also needs to consider radical and Marxist critiques of contemporary schooling.

But their topics can only be taken up on the basis of an understanding of educational situations which arises from within the world of everyday life. It is here where questions of educational value and meaning are decided.

This is not to say that the dynamics of social integration and systems-integration do not need explication. For everyday life certainly is subject to pressures coming from outside the range of activities coordinated in it. The organization of daily life is not always visible in it (Smith, 1980).

But this observation ought not mislead us into believing that we can penetrate the dynamics of rationalization in modern societies by placing ourselves at a fictitious endpoint of this process. Sometimes Habermas writes as if anticipating this endpoint was the only way to make sense of the process or to identify the absence of sense in it. But such a comprehensive view is only available from the point of view of theories and not from the perspective of daily life.

It is only from the perspective of theory that the conflict between technologies intruding into the communicative relations of everyday life and everyday life itself can be made out to subvert the very cultural foundations of society. 
From the perspective of everyday life our cultural situation may appear to be grim. But the possibility of everyday life itself disappearing just is not conceivable.

One can agree with Habermas that threats to the survival of the human species are not merely physical. They may indeed include "attacks" on the very foundations of individual and collective identity resulting from the erosion of cultural traditions. It is Habermas' strength to have drawn attention to this more than any other theorist. But we still need to understand how these threats become visible in everyday life.

Thus, we are still at a loss to understand in what way a change of this or that practice, a change from traditional pedagogy (taken in the broadest sense) to teaching based on instructional technologies, is a good or a detrimental change. We cannot merely apply general considerations of the kind Habermas has developed to particular cases. We need to understand better what we are applying general consideration to, so that we can also determine which general considerations do indeed apply, in what way, and what force they might have. In this sense, a theory of the society is dependent upon a reflection and analysis of the practical organization of daily scenes of social action. It must be supplemented by a study of the social organization of practices occurring in determinate settings. We can then reflect on what it means to have to make sense of, to cope with, these particular settings as a matter in which the sense or the senselessness of one's activities (in relation to the position of groups in social life) can become available as topics of possible practical orientation. This reflection is the task of a hermeneutically radicalized phenomenology.

\section{Notes}

1. I wish to thank the students who participated in my course which I taught at the University of Alberta (Faculty of Education) during July, 1983, for having helped me articulate the perspective on the social service professions to be found in the first part of this paper.

2. Paulo Freire's approach is significantly different from now current conceptions of critical pedagogy. Quite apart from the fact that Freire's programme was designed as a form of literacy training for Third World peasants, the philosophical foundations for Freire's position as discussed in his Pedagogy of the Oppressed consist of a reinterpretation of existentialism and Marxism or elements thereof which suggest significant parallels to hermeneutics and to communications theory in critical theory. Most present North American conceptions of a critical pedagogy neglect the existentialist and hermeneutical elements in Freire's thought, which reflect his proximity to the theology of liberation.

3. In my discussion of the debate between Habermas and Gadamer, I have discussed some of the differences between Habermas and Gadamer, also with respect to the different conceptions of reflection involved (cf. also Misgeld, 1978 and 1981 b.).

4. Niklas Luhmann is an encyclopedic author. He has published up to twenty books in German. Among them are discussions of central concepts of systems theory as well as applications of it to law, religion, education and "love" as a socially integrative "mechanism." Luhmann is Habermas' major competitor in contemporary German sociology. He has engaged in a signfiicant debate with Habermas which has led to numerous analyses of the issues topical in the debate. 


\section{Bibliography}

Beekman, T. (1983). Human Science as a Dialogue with Children. Phenomenology and Pedagogy, 1,(1) 36-44.

Freire, P. (1971). Pedagogy of the Oppressed, New York: Herder \& Herder.

Freire, P. (1970). Cultural Action for Freedom. Harvard Educational Review Monograph Series No. 1.

Gadamer, H. G. (1974). Truth and Method. New York: Seabury Press.

Gadamer, H. G. (1976). The Scope and Function of Hermeneutical Reflection. In H. G. Gadamer, Philosophical Hermeneutics. Berkeley: University of California Press.

Giorgi, A. (1983). Common Sense and Science: Adversaries or Friends? A comment on Luckmann. Phenomenology and Pedagogy, 1 (1) 80-88.

Habermas, J. (1981). Theorie des Kommunikativen Handelns. 2 Volumes. Frankfurt: Suhrkamp. To be published in English in 1983 (fall) and 1984(summer) by Beacon Press, Boston.

Habermas, J. (1979). Communication and the Evolution of Society. Boston: Beacon Press.

Habermas, J. (1970). Knowledge and Human Interests. Boston: Beacon Press.

Habermas, J., \& Luhmann, N. (1971). Theorie der Gesellschaft oder Sozialtechnologie? Frankfurt: Suhrkamp.

Illich, J. (1978). The Right to Useful Unemployment. New York: Marion Boyars Publishers Ltd.

Illich, J. (1977). Disabling Professions. London: Marion Boyers Publishers Ltd.

Kibler, R., et al. (1981). Objectives for Instruction and Evaluation. Boston: Allyn \& Bacon, Inc.

Luhmann, N. (1981). The Differentiation of Society. New York: Columbia University Press.

Luckmann, T. (1983). Common Sense, Science and the Specialization of Knowledge. Phenomenology and Pedagogy, 1(1), 59-76.

Maclntyre, A. (1981). After Virtue: A Study in Moral Theory. Notre Dame, IN: University of Notre Dame Press.

Misgeld, D. (1976). Critical Theory and Hermeneutics: The Debate between Habermas and Gadamer. In J. O'Neill, (Ed.), On Critical Theory. New York: Seabury Press; London: Heinemann.

Misgeld, D. (1977). Discourse and Conversation. The Theory of Communicative Competence and Hermeneutics. Cultural Hermeunetics, 4(4), 321-344.

Misgeld, D. (1981a). Ultimate Self-Responsibility, Practical Reasoning, and Practical Action: Habermas, Husserl \& Ethnomethodology on Discourse and Action. Human Studies, 3, 255-270.

Misgeld, D. (1981b). Science, Hermeneutics and the Utopian Content of the Liberal Democratic Tradition. New German Critique, 21(22), 123-144.

Misgeld, D. (1983). Common Sense and Common Convictions: Sociology as a Science, Phenomenological Sociology and the Hermeneutical Point of View. Human Studies, 1(1), 1-32. Also to be published in D. Olson, \& F. V. Holthorn, (Eds.), Common Sense: The Ground of Science.

Schutz, A. (1973). Collected Papers, Vol. I. The Hague, Netherlands: Martinus Nijhoff.

Schutz, A. (1971). Collected Papers, Vol. II. The Hague, Netherlands: Martinus Nijhoff.

Smith, D. (1980). A Sociology for Women. In J. Sherman, E. Beck, (Eds.), The Prism of Sex. Madison: University of Wisconsin Press.

Suransky, V. (1980, May). Phenomenology as an Alternative Research Paradigm and a Force for Social Change. Journal of the British Society for Phenomenology, 11(2), 163-179.

Taylor, C. (1971). Interpretation and the Sciences of Man. Review of Metaphysics, $25(3), 1,32,35-45$. 